\title{
Fast and robust inversion of earthquake source rupture process and its application to earthquake emergency response*
}

\author{
Yong Zhang* Yun-tai Chen and Lisheng Xu \\ Institute of Geophysics, China Earthquake Administration, Beijing 100081, China
}

\begin{abstract}
Fast inversion of source rupture process for significant earthquake is introduced and applied to earthquake emergency response. We retrieve and use the apparent source time functions (ASTFs) to stabilize the rupture process inversion, aiming to get the rupture process results correctly and quickly. The applications to 22 significant earthquakes occurred between January 2009 and July 2011 show an average inversion time consumed of about four hours, suggesting a high efficiency of this method, which much improves the inversion speed of the rupture process and is helpful in earthquake disaster mitigation and relief.
\end{abstract}

Key words: rupture process; earthquake emergency; disaster mitigation; real time seismology CLC number: P315. $3^{+}$, P315.0 Document code: A

\section{Introduction}

Nowadays, seismologists determine and release epicentral locations taking several seconds to several minutes, and obtain moment tensor solutions about several hours after earthquake occurrence. These results make it possible to better understand the fault mechanism and related scientific researches. For the earthquake emergency response, however, it is still not enough to assess the earthquake disaster by using only the epicentral location and moment tensor solution. In addition, although the aftershock location provides rough estimation of the fault dimension of the main shock, it depends on the occurrences of the aftershocks and cannot give the information of fault slip heterogeneity. Therefore, spatio-temporal images of the earthquake rupture process are highly needed since they detailedly describe the earthquake source kinematics, and give valid information on the rupture

\footnotetext{
* Received 9 December 2011; accepted in revised form 15 March 2012; published 10 April 2012.

+ Corresponding author. e-mail: zhangyong@cea-igp.ac.cn

(C) The Seismological Society of China, Institute of Geophysics, China Earthquake Administration, and Springer-Verlag Berlin Heidelberg 2012
}

direction and fault slipped range. Besides, correct rupture process result is helpful to estimate intensity in the epicentral region. On this aspect, Zhang et al. (2009a) have found that the region of large coseismic surface deformation usually well corresponds to meizoseismal area, although the relation between the isoseismals and the surface deformation is not very clear at present.

Therefore, rupture process result of large/ disastrous earthquake is believed to play an important role in earthquake emergency response (e.g. disaster relief and mitigation). In recent years, several international institutions of geophysics, such as USGS, Tokyo University, Caltech and UCSB, have been working on the routine determination of rupture process. However, they usually released their results about several days after the earthquake occurrence, causing those results hardly be used to the earthquake emergency response.

In this paper, we introduce our fast inversion of the rupture process, and its application to the earthquake emergency response. We improve the efficiency of the inversion so much that in general we need only 3 to 5 hours for the inversion of each earthquake. This ensures the fast inversion results can be used effectively in the earthquake disaster mitigation and relief. 


\section{Methods and data}

On the basis of the comparison between the two typical inversion methods for repture process, i.e. apparent source time functions (ASTFs) method and direct wave inversion method (Chen and $\mathrm{Xu}, 2000$; Zhang et al., 2010a), we divide the inversion into two steps. Firstly, we retrieve the ASTF, and get a rough estimation on the overall rupture direction by analyzing ASTFs with their seismic Doppler effects. Secondly, based on the rough estimation, we directly invert the seismograms for a detailed rupture process. During the second-step inversion, the ASTFs constrain and stabilize the waveform inversion in an empirical way. We try different parameters for the waveform inversion, until the results satisfy the following two conditions: (1) They are consistent with the Doppler effects shown in the azimuthdependent ASTFs; (2) The obtained source time function (STF) should be similar to the average ASTF (the superposition of all ASTFs).

We construct a semiautomatic operation process to fast and stably carry out the rupture process inversion, which contains several useful program modules, such as the teleseismic data processing, fast calculation of Green's function, ASTFs analysis, inversion parameters' setting, and quickly-display of the inversion results. In the data processing module, the $\mathrm{P}$ waves are picked by using the existing hypocentral locations, and their signal-to-noise ratios are examined automatically. And then, the teleseismic stations are reselected by an azimuthal filter with an interval of about two to five degrees to ensure a uniform coverage of the stations over the epicenter. To fast calculate the Green's functions, we optimize the calculation parameters (e.g. set the slowness window to be $0-0.1 \mathrm{~s} / \mathrm{km}$ for $\mathrm{P}$ waves calculation so that the length of Green's function can be reduced much) and parallelize the procedures. For the teleseismic data inversion, we only calculate the Green's function from the subfault where the hypocenter is located to each station, Green's functions of other subfaults to stations are obtained by shifting the calculated ones in time domain. As a result, we usually spend less than one minute to calculate Green's functions for each earthquake. The ASTFs are retrieved by using Projected Landweber Deconvolution (PLD) method (Bettero et al., 1997), which helps us to stabilize the deconvolution by invoking reasonable constraints (i.e. positivity, causality, and limited duration) on the ASTFs. The waveform inversion method of Zhang et al. (2009a) was revised for the rake variation inversion and used in the study. In order to quickly display the inversion result, the ETOPO1 data (Amante and Eakins, 2009) around the world is prepared to make the results of pictures/animations be automatically generated. With these several convenient modules, we design a software interface operated with only mouse clicks, aiming to save time for each inversion, and obtain the rupture process results as quickly as possible.

The teleseismic $\mathrm{P}$ waves with the epicentral distance of $30^{\circ}$ to $90^{\circ}$ on their vertical components are downloaded from the Incorporated Research Institutions for Seismology (IRIS) website and used in this study. The Green's function is calculated by using the method (Kennett, 1983) based on the IASPEI91 model (Kennett and Engdahl, 1991).

\section{Results and applications}

We have fast inverted the teleseismic waves of 22 significant earthquakes occurred between January 2009 and July 2011 (Figures 1 and 2) for the rupture process. As shown in Figure 2, it takes about 3 to 5 hours to get the results for most of the 22 earthquakes except for the first four earthquakes occurred when the operation process have still not been completely constructed. The average time consumed is about 4 hours, which is much less than several days that the several institutions (e.g. USGS, Caltech, Tokyo University, UCSB) usually spend to release their result, and is fast enough to be applied to the earthquake emergency response.

In this paper, the 15 July 2009 New Zealand $M_{\mathrm{W}} 7.8$ earthquake and the 27 February 2010 Chile $M_{\mathrm{W}} 8.8$ earthquake, whose fast inversions had been introduced before (Zhang et al., 2009b; 2010b), are taken as two examples for the introduction and discussion of fast rupture process inversion.

\subsection{July 2009 New Zealand $M_{\mathrm{W}} 7.8$ earth- quake}

The 15 July 2009 New Zealand $M_{\mathrm{W}} 7.8$ earthquake occurred off coast of the south island of New Zealand. From the fast report of USGS, the hypocenter was located at $\left(45.7^{\circ} \mathrm{S}, 166.6^{\circ} \mathrm{E}\right.$, with focal depth $35 \mathrm{~km}$ ) and the origin time was 2009-07-15, 09h22min32s (UTC). As Figure 3a shows, P waves of 28 teleseismic stations are used in the inversion. From the retrieved azimuth-dependent ASTFs (Figure $3 \mathrm{~b}$ ), we can get the estimation on the rupture characteristics as follows. (1) There is only one major rupture event during the rupture process; (2) The peak values of the azimuth-dependent ASTFs appear 


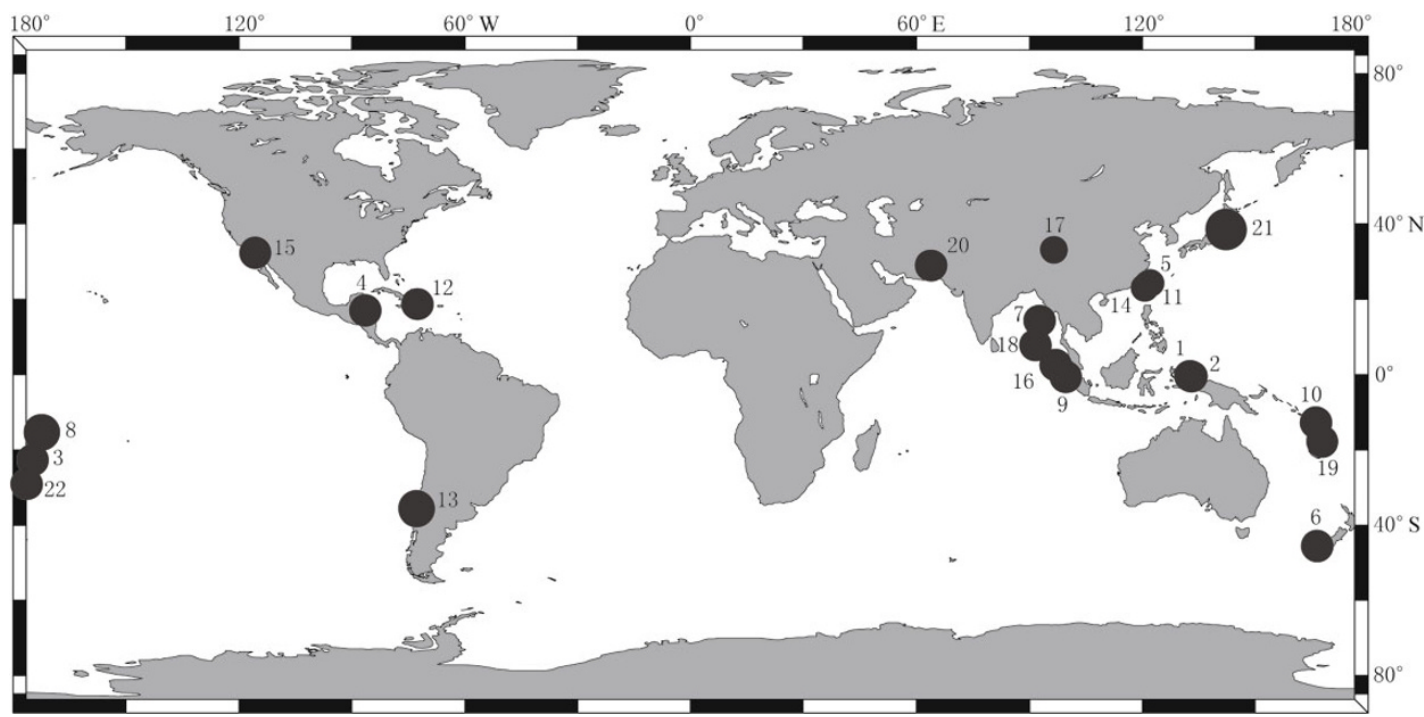

Figure 1 Epicentral distribution of 22 significant earthquakes world wide whose rupture process have been fast inverted. The numbers beside the circles denote the serial number of the 22 earthquakes.

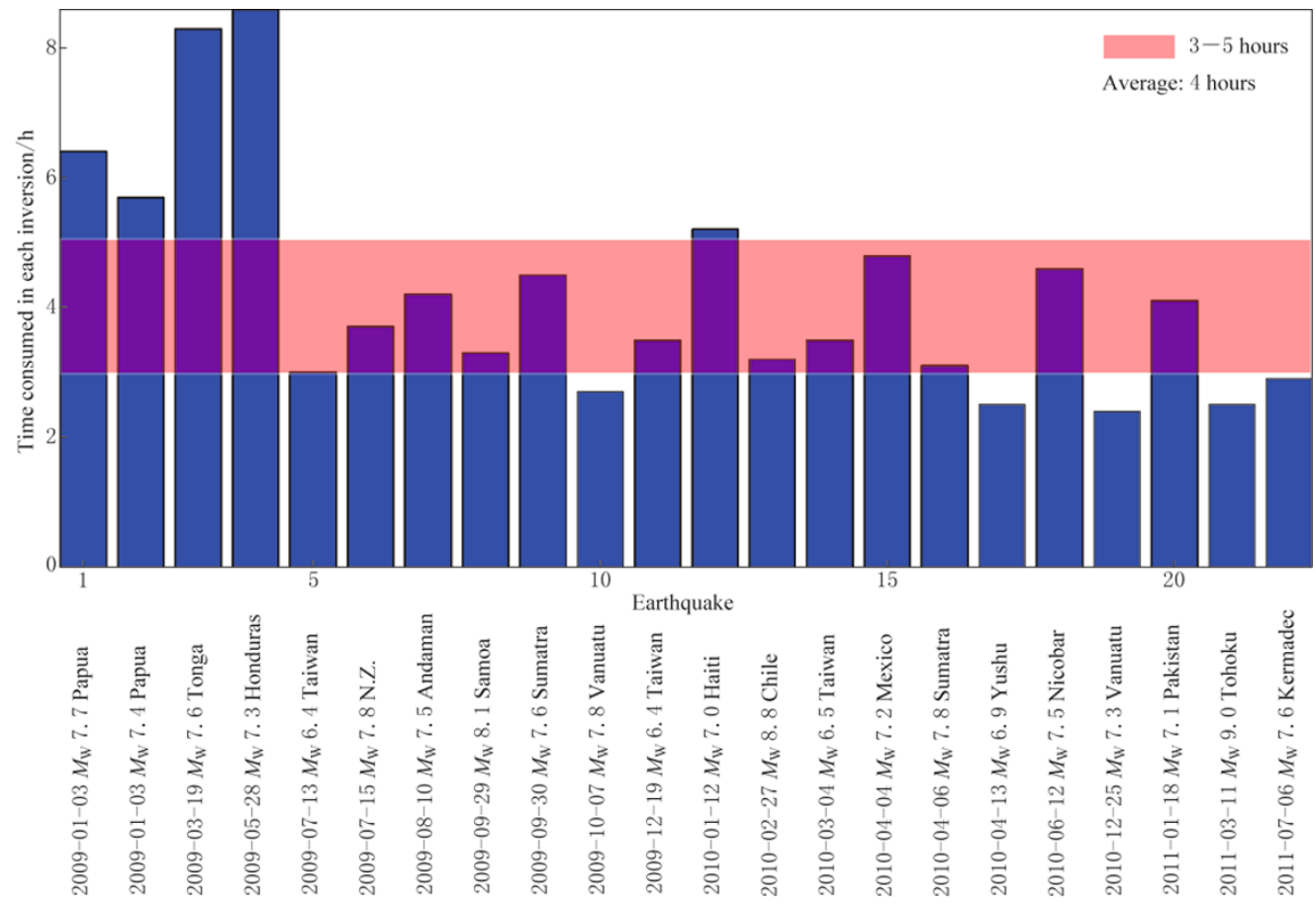

Figure 2 Time consumed in the fast rupture process inversion of the 22 significant earthquakes. The eathquake serial number is the same as that in Figure 1.

at different times: the ASTFs at the azimuth of about $70^{\circ}$ reach their peaks latest, indicating that the rupture mainly propagates towards southwest.

The results obtained 3.75 hours after the earthquake occurrence from the direct inversion of seismic data are shown in Figure 3. Based on the regional geological structure, the fault plane, with strike of $27^{\circ}$ and dip of $33^{\circ}$ (from USGS report), is taken as the causative fault in this inversion. From the inversion results, it can be found that the source time function (Figure 3c), with duration of about $40 \mathrm{~s}$, seems very simple and has only one major sub-event which releases about $93 \%$ scalar moment of the earthquake. On the fault plane, there is also only one slip-concentrated patch located to the 

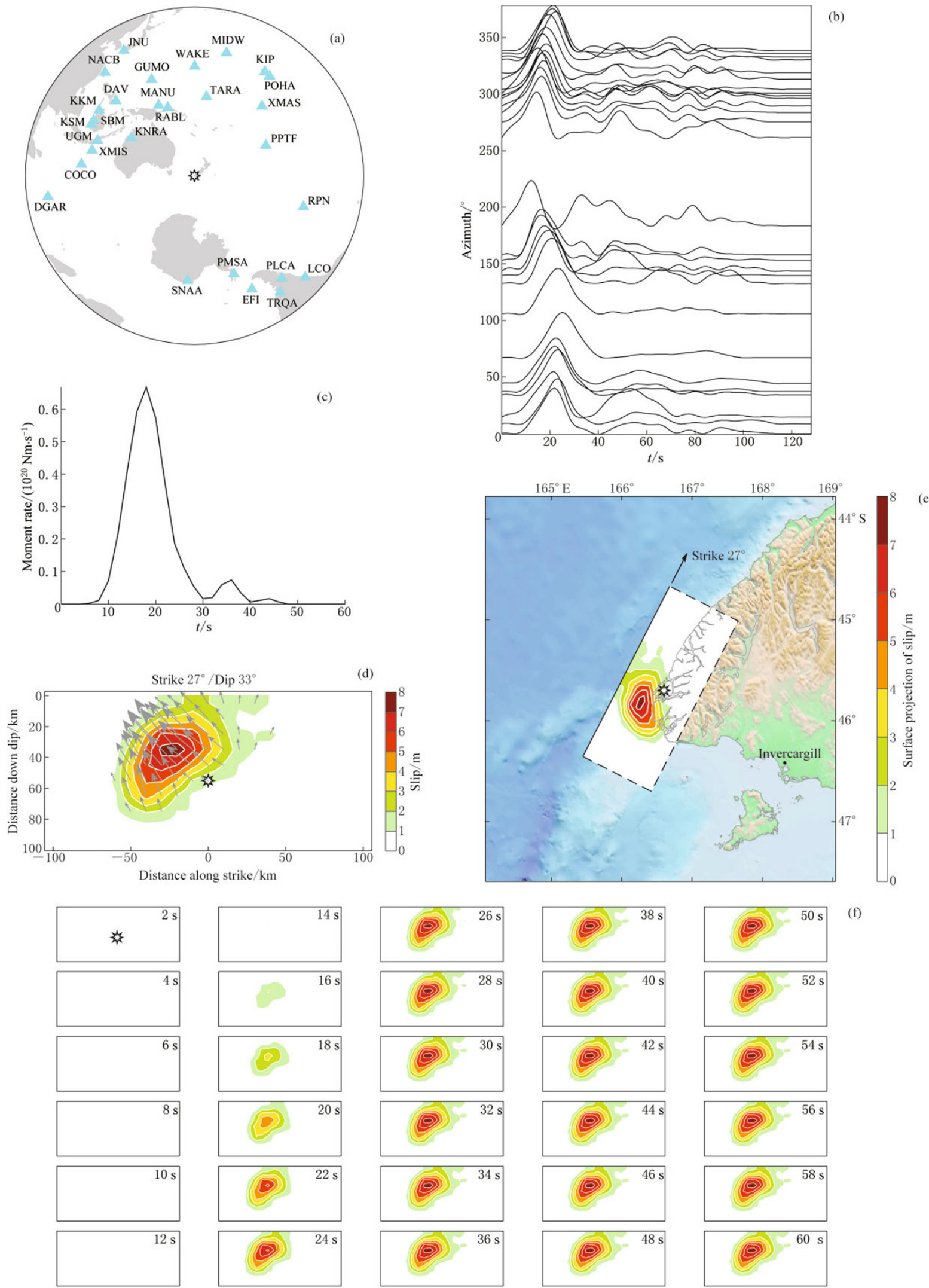

(f)
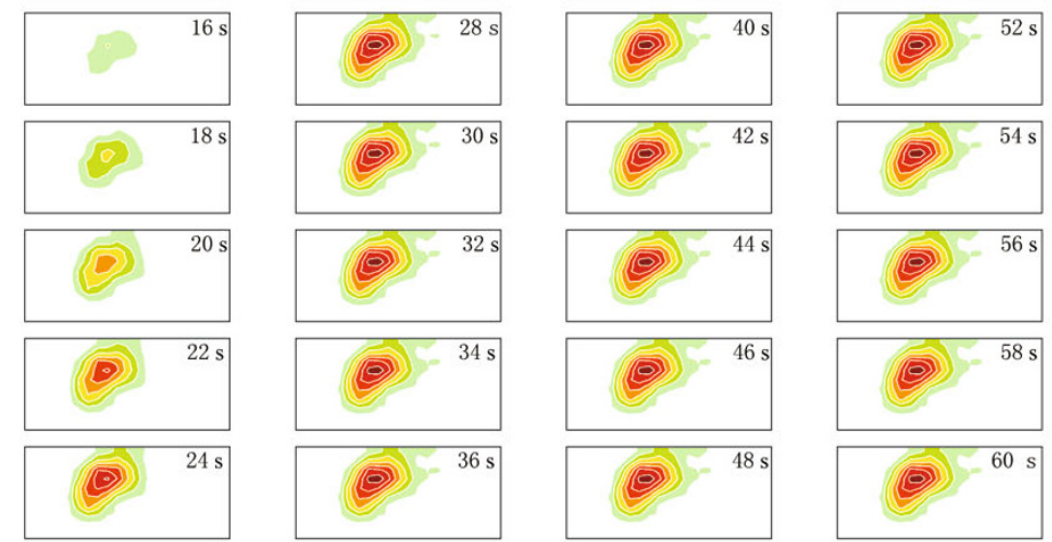

Figure 3 Inversion results of the 15 July 2009 New Zealand earthquake. (a) Distribution of epicenter and seismic stations used in the inversion; (b) Azimuth-dependent ASTFs; (c) Source time function; (d) Static slip distribution on the fault plane; (e) Surface projection of the static slip distribution; (f) Temporal variation of the slip distribution on the fault. 
upper left of the hypocenter (Figure 3d). Overall, the slip did not break through the seabed, but caused a large slip patch in depth of about 10-70 km (red-orangeyellow areas in Figure 3d) with the maximum slip of about $7.7 \mathrm{~m}$. From the surface projection of the slip distribution (Figure 3e), it is found that the slipped area mainly locates southwest of the epicenter, which is consistent with the estimation by analyzing the azimuthdependent ASTFs. The temporal slip variation on the fault (Figure 3f) shows a relatively simple rupture process of this earthquake: the rupture propagated unilaterally towards upper left of the hypocenter and caused a slip patched in that direction.

On the basis of the rupture process results, it can be inferred that there would not be large-scale tsunami because the major fault slip located in depth would not cause large surface deformation on seabed near the epicenter. Besides, because the fault slip mainly occurred offshore, the earthquake damage would not be serious on the land of the South Island of New Zealand.

We compare the static slip distribution in our results (labeled as CEA, as Figure 4 shows) with others obtained and released by Tokyo University (http://taro.eri.u-tokyo.ac.jp/saigai/20090715eq/ 200907015.html) and USGS (http://earthquake.usgs. gov/earthquakes/eqinthenews/2009/us2009jcap/finite_ fault.php). It is found that the three results are very similar to each other, even though they were obtained with different datasets and inversion methods, suggesting that our fast rupture process result is reliable.
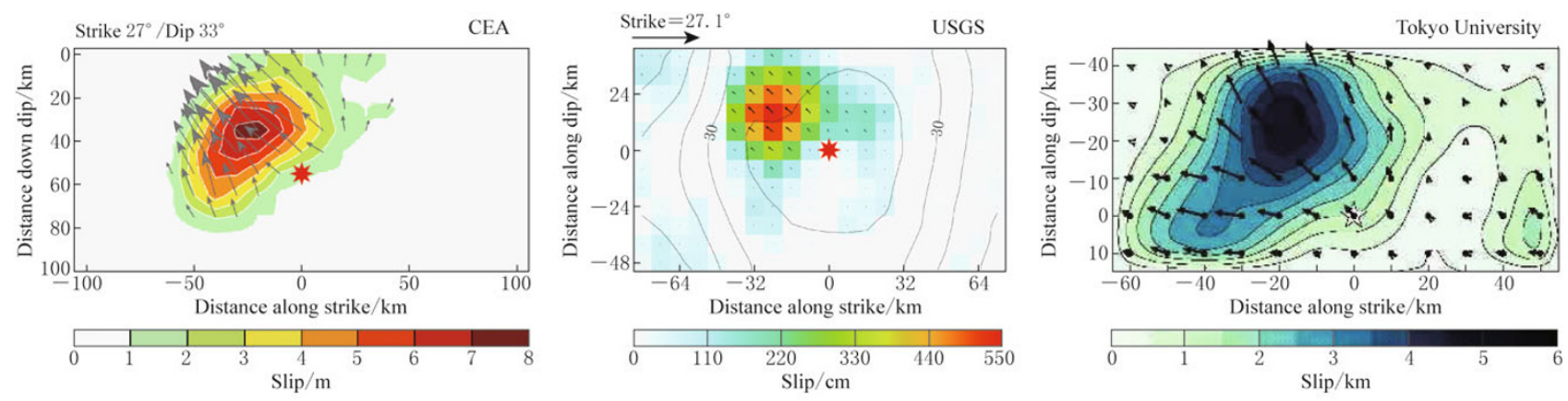

Figure 4 Comparison of the static slip distributions on the fault plane for the 15 July 2009 New Zealand earthquake obtained by different institutions.

\subsection{February 2010 Chile $M_{\mathrm{W}} \mathbf{8 . 8}$ earthquake}

The 27 February 2010 Chile $M_{\mathrm{W}} 8.8$ earthquake with epicenter of $\left(35.8^{\circ} \mathrm{S}, 72.7^{\circ} \mathrm{W}\right)$, focal depth of $35 \mathrm{k}$ $\mathrm{m}$, origin time of $2010-02-27,06 \mathrm{~h} 34 \mathrm{~min} 17 \mathrm{~s}$ (UTC), is the largest earthquake since the $1960 M_{\mathrm{W}} 9.5$ earthquake occurred near Chile. About 3.2 hours after the occurrence of this earthquake, we obtained and released the fast estimation of the rupture process of this earthquake by inverting the $\mathrm{P}$ waves of 18 telesesimic stations shown in the Figure 5a.

The retrieved azimuth-dependent ASTFs (shown in Figure 5b) show that the rupture process is quite complex. (1) The source duration is about $150 \mathrm{~s}$. (2) There are at least four sub-events occurred during the rupture process. (3) The seismic Doppler effects contained in the ASTFs do not show obvious rupture directivity, indicating the earthquake should be a complex bilateral rupture event.

By using the fault parameters of the $\mathrm{W}$ phase moment tensor results released by USGS, we chose the fault plane striking $16^{\circ}$ and dipping $14^{\circ}$ as the causative fault which was the most consistent with the tectonic bound- ary between the Pacific Plate and the South America Plate. The inversion results show that the earthquake has a complex rupture process consisting of several subevents (Figure 5c). The rupture propagated bilaterally to north and south, with a maximum slip of about 8.3 $\mathrm{m}$ near the hypocenter. From the image of static slip distribution, there are three slip-concentrated patches, one is near the hypocenter and the other two are located to the south and north of the epicenter (Figure $5 \mathrm{~d})$, respectively. With the consideration of the surface projection of the slip distribution (Figure 5e) and the locations of the two largest cities (Santiago and Concepcion) in Chile, we find that Concepcion may be shaken more seriously than Santiago because it locates closer to the ruptured fault. The temporal variation of the slip on the fault (Figure 5f) shows that the rupture propagated bilaterally toward north and south simultaneously.

USGS (http://earthquake.usgs.gov/earthquakes/ eqinthenews/2010/us2010tfan/finite_fault.php), UCSB (http://www.geol.ucsb.edu/faculty/ji/big_earthquakes/ 2010/02/27/chile_2_27.html) and Caltech (http:// tectonics.caltech.edu/slip_history/2010_chile/index.html) 

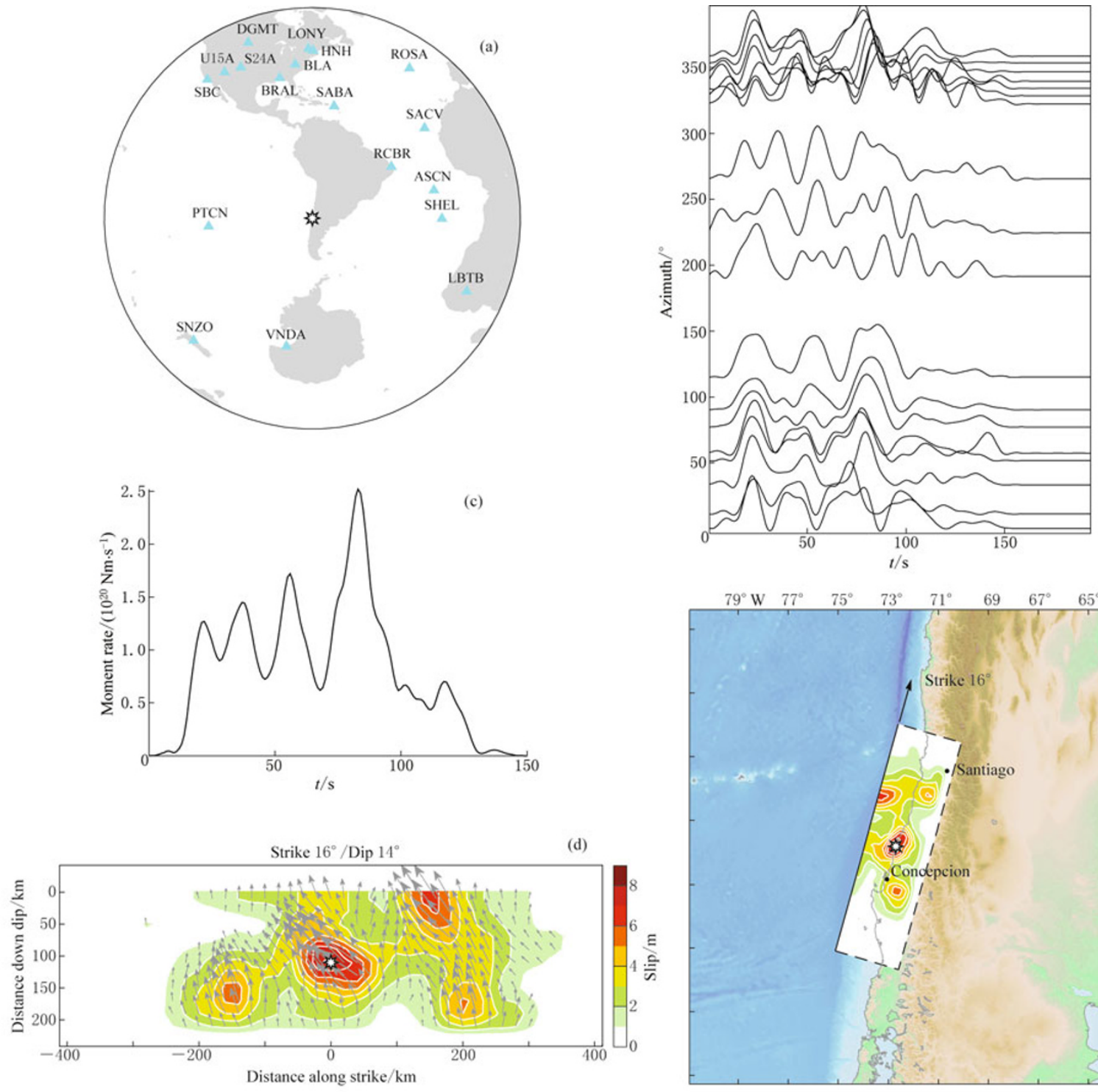

(b)
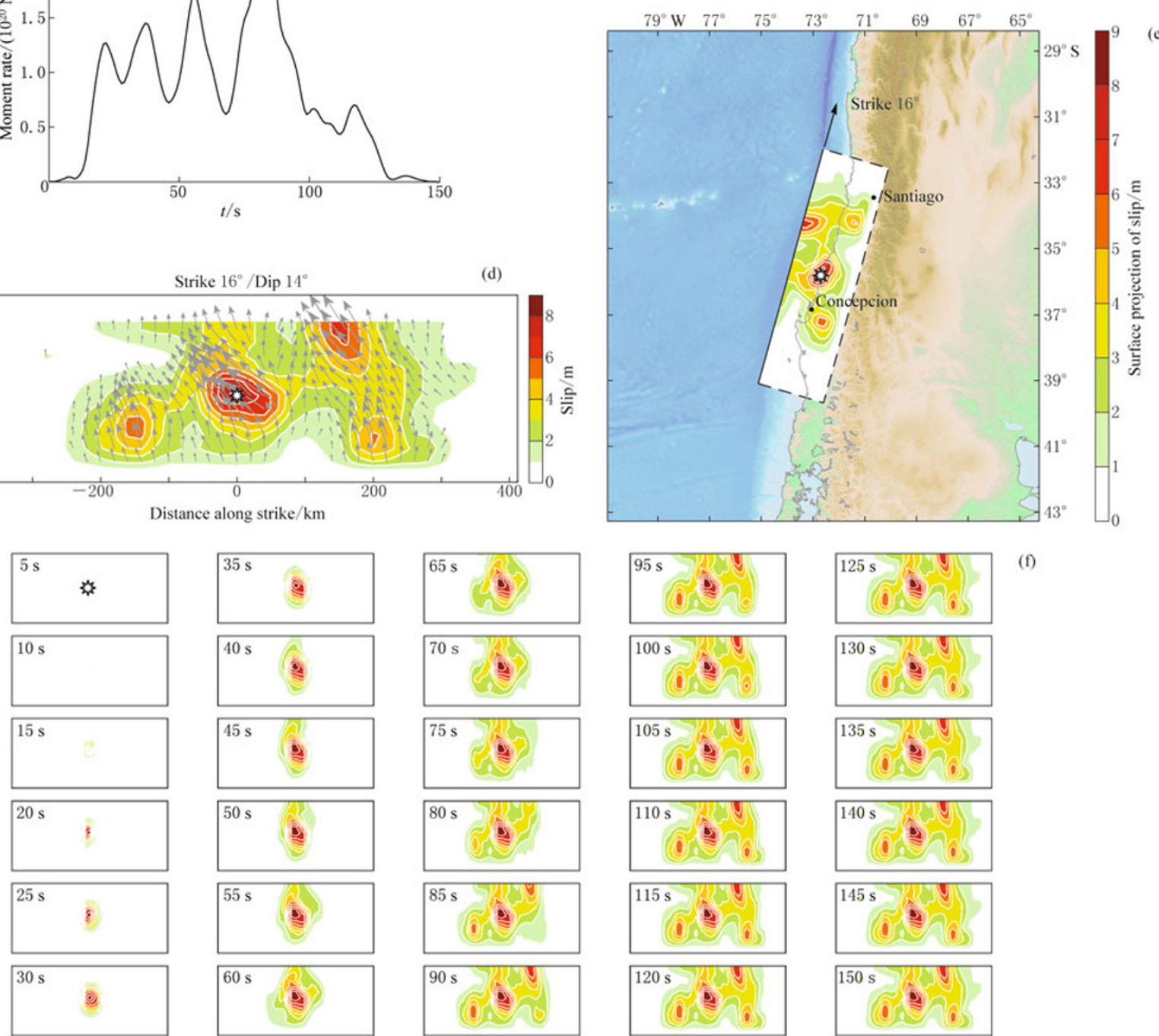

(f)
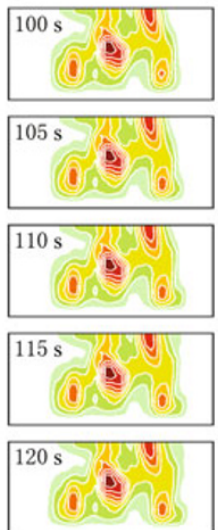
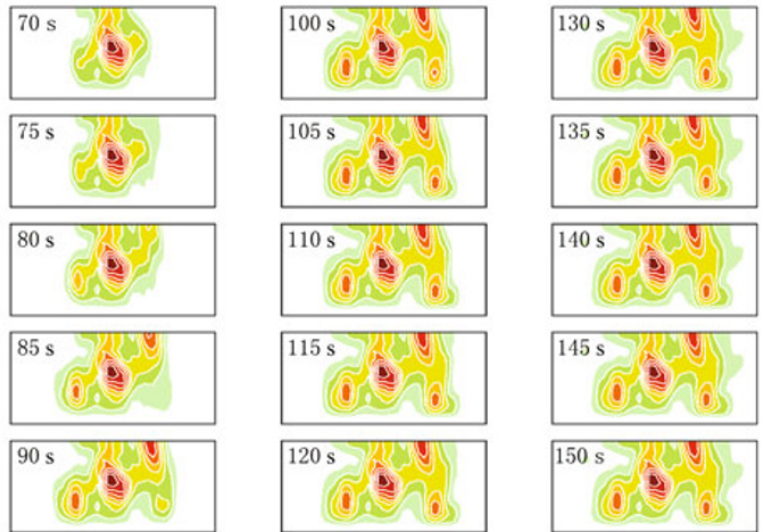
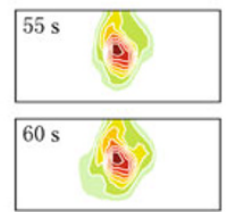

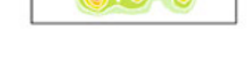

Figure 5 Inversion results of the 27 February 2010 Chile earthquake. (a) Distribution of epicenter and seismic stations used in the inversion; (b) Azimuth-dependent ASTFs; (c) Source time function; (d) Static slip distribution on the fault; (e) Surface projection of the static slip distribution; (f) Temporal variation of the slip distribution on the fault. 
also determined the rupture process of the 2010 Chile earthquake. As Figure 6 shows, the preliminary results released by these institutions are quite different, but it still can be found that the updated result of USGS is the most similar result to ours, suggesting that our results have been confirmed by the subsequent study or investigation.
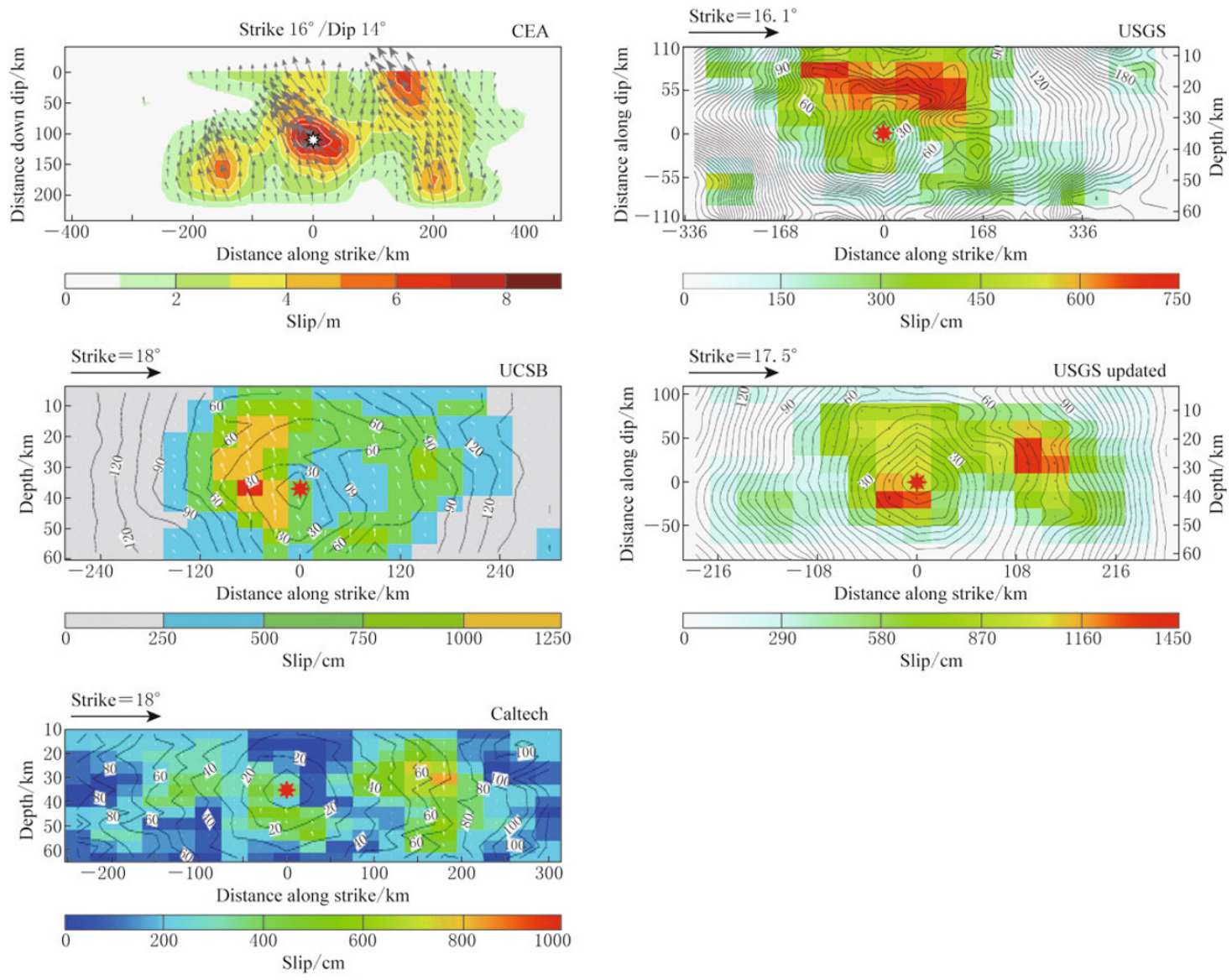

Figure 6 Comparison of the static slip distributions on the fault plane for the 27 February 2010 Chile earthquake.

\section{Discussion and conclusions}

In this paper, we introduce the fast rupture process inversion and its application to the earthquake emergency response. Based on the rupture process results, we get useful information on the source rupture behaviors, such as the fault dimension, rupture direction, slip amplitude, surface breakage of the slip, each of which influences the intensity distribution much in the meizoseismal area. Thus, we can estimate the earthquake disaster distribution and give useful suggestions to the disaster relief and mitigation.

This fast rupture process inversion is also useful to the real time seismology. In recent years, seismologists around the world have focused on the real time seismology (Kanamori et al., 1997), one of whose ma- jor purposes is to obtain the source characteristic and give early warnings for disastrous earthquake as soon as possible. However, the existing early warning systems are based on the basic source parameters (i.g. hypocentral location, origin time and magnitude), which is not enough for the fast estimation to the earthquake disaster and tsunami. Thus, fast inversion of the seismic moment tensor and rupture process are highly demanded, and there have been some relevant works (Kanamori and Rivera, 2008). This paper offers an efficient way to the real/quasi-real time investigation for the earthquake rupture process.

However, there are some problems to be discussed for this work. The first is about the data acquisition. To ensure a good azimuthal coverage of the teleseismic data over the epicenter, we usually have to begin to 
download the data till 1-2 hours after the earthquake occurrence when the data released at the IRIS website is enough for the inversion, and this is almost one half of the time consumed ( $\sim 4$ hours) for each inversion (Figure 2). Secondly, as we know, the rupture process inversion is based on the hypocentral location and fault parameters. Thus, uncertainties of hypocentral locations and fault parameters closely disturb the inversion results of rupture process. Different epicentral locations lead to different positions of the ruptured fault, also, the inaccuracy of the focal depth (depth of the rupture initiation point) would result in inaccurate/false estimation of the surface breakage, which is very important for the fast assessment of the earthquake disaster distribution. Besides, the fault parameters (strike and dip) also lead to different rupture process results by affecting the direction of rupture propagation. Therefore, the reliability of the fast rupture process inversion heavily depends on the seismic location and moment tensor solution, and it is necessary for us to pay attention to the uncertainties of the rupture process results caused by these factors while investigating the earthquake disaster distribution.

In the future, we plan to improve the fast rupture process inversion for higher efficiency and accuracy in several following aspects: (1) to build an automatic system for data downloading to reduce the time in data acquisition, which would help to get the seismic data much faster than before; (2) to construct a database of Green's functions to save the calculation time of Green's functions and make it feasible to consider the path effect from each subfault to each station in order to get a more detailed and reliable inversion result; (3) to make a further research on the inversion method to improve its robustness by optimizing the existing constraints or introducing new physical and reasonable constraints for the inversion; (4) to establish a website to timely and routinely release the rupture process results; (5) to develop a joint inversion method for fast rupture process inversion using seismic data and geodetic data, and to make a preparation for its application to the earthquake emergency response of significant earthquakes in the future when the geodetic data can be fast accessed.

Acknowledgements This work is supported by the National Natural Science Foundation of China
(No. 41090291) and the Research Project in Earthquake Science, CEA (Nos. 201108002 and 200808068).

\section{References}

Amante C and Eakins B W (2009). ETOPO1 1 Arc-Minute Global Relief Model: Procedures, Data Sources and Analysis. NOAA Technical Memorandum NESDIS NGDC24, 2009, 19.

Bertero M, Bindi D, Boccacci P et al. (1997). Application of the projected Landweber method to the estimation of the source time function in seismology. Inverse Problems 13: $465-486$.

Chen Y T and Xu L S (2000). A time-domain inversion technique for the tempo-spatial distribution of slip on a finite fault plane with applications to recent large earthquakes in the Tibetan Plateau. Geophys J Int 143: 407-416.

Kanamori H, Hauksson E and Heaton T (1997). Real-time seismology and earthquake hazard mitigation. Nature 390: $461-464$

Kanamori H and Rivera L (2008). Source inversion of W phase: Speeding up seismic tsunami warning. Geophys $J$ Int 175: 222-238.

Kennett B L N (1983). Seismic Wave Propagation in Stratified Media. Cambridge University Press, Cambridge, 1339.

Kennett B L N and Engdahl E R (1991). Travel times for global earthquake location and phase identification. Geophys J Int 105: 429-465.

Zhang Y, Xu L S and Chen Y T (2010a). Rupture process of April 62009 L'Aquila Italy $M_{\mathrm{W}} 6.3$ earthquake: a comparison between apparent source time function method and direct wave inversion method. Chinese $J$ Geophys 53(6): 1 428-1 439 (in Chinese with English abstract).

Zhang Y, Feng W P, Xu L S, Zhou C H and Chen Y T (2009a). Spatio-temporal rupture process of the 2008 great Wenchuan earthquake. Science in China (Series D) 52(2): 145-154.

Zhang Y, Xu L S and Chen Y T (2009b). Fast inversion of the rupture process of 2009 July 15 off west coast of South Island of New Zealand earthquake. Acta Seismologica Sinica 31(6): 699-701 (in Chinese with English abstract).

Zhang Y, Xu L S and Chen Y T (2010b). Fast inversion of the rupture process of 27 February 2010 Chile earthquake. Acta Seismologica Sinica 32(2): 242-244 (in Chinese with English abstract). 